\title{
Evidence for the existence of an oligomeric, non-DNA-binding complex of the progesterone receptor in the cytoplasm
}

\author{
S. Passinen, ${ }^{*}$ T. Ylikomi*o \\ *Department of Cell Biology, Medical School, University of Tampere; 'Department of Clinical Chemistry, \\ Tampere University Hospital, Tampere, Finland
}

(C)2003, European Journal of Histochemistry

Steroid receptors are found as a hetero-oligomeric complex in cell extracts. Due to the dynamic interaction between receptor-associated proteins and receptors, it is difficult to study the oligomeric complex in living cells. Here this was attempted in cells in which the interaction was stabilized by introducing molybdate into the cells or by incubating the cells at low temperature. The complex was studied with an antibody $(\alpha D)$ recognizing only the dissociated form of the chicken progesterone receptor (PR) and with antibodies (PR22, PR6). Recognizing also oligomeric forms of the receptor. When wild-type chicken PR was transfected, all antibodies showed nuclear staining. Molybdate or cold treatment of cells resulted in cytoplasmic accumulation of the PR as detected with PR22/PR6. $\alpha D$, however, stained predominantly the nuclear PR in treated cells. These findings suggest that when the oligomeric complex of the PR is stabilized in intact cells in vivo and then crosslinked with paraformaldehyde, a portion of the cytoplasmic receptor is seen as an oligomeric complex, whereas, in the nucleus, most, if not all receptor molecules are in dissociated form.

Key words: heat shock protein 90, progesterone receptor, oligomeric complex, immunohistochemistry, molybdate.

Correspondence: Timo Ylikomi, Medical School, 33014 University of Tampere, Finland. Phone: international +358 . 3.2156733. Fax: international +358.3.2156170.

E-mail: timo.ylikomi@uta.fi

Paper accepted on March 3, 2003

European Journal of Histochemistry 2003; vol. 47 issue 3 [Jul-Sept]: 201-208
Steroid receptors belong to a large family of nuclear receptors functioning as ligand-regulated transcription factors. Receptor function is mediated by receptor-interacting proteins; co-activators interact with agonist-occupied receptors and mediate transcription activation while co-repressors interact with non-liganded or antagonist-occupied and mediate transcription repression. Ligand binding induces a considerable change in the structure of the ligandbinding domain (LBD), affecting the surface exposition of the receptor which dictates the interaction of the cofactors [Moras and Gronemeyer 1998, Renaud et al. 1995, Wurtz et al. 1996]. The earliest known receptor-interacting protein is Hsp90 [Dougherty et al. 1984]. It is known to interact in vitro with the LBD of the steroid receptor in a ligand-dependent manner: it binds to non-liganded steroid receptor but not to agonist-occupied receptor. Non-liganded steroid receptor LBDs act as intramolecular repressors of the activation functions of steroid receptors as well as of heterologous proteins when covalently linked to them [Picard et al. 1988]. Deletion of the LBD generates a constitutively active steroid receptor which does not form a stable oligomeric complex with Hsp90 in vitro. In view of these data, it has been proposed that the Hsp90 interaction is responsible for the repressor function of non-liganded LBDs [Scherrer et al. 1993]. Binding of Hsp90 interferes with the DNA binding of the receptor, which has been regarded as one possible mechanism by which Hsp90 functions as a corepressor. Hsp90 is also required for proper ligand binding of the glucocorticoid receptor [Bresnick et al. 1989]. It has been proposed that the oligomeric form of steroid receptors represents a poised conformation, inactive but ready to interact with the ligand. Ligand binding is thought to dissociate the complex and allow receptor binding to DNA [Baulieu 1987, Bohen et al. 1995]. It should be noted that such a mechanism is confined solely to steroid receptors, as other nuclear receptors, such as retinoid-, thyroid- and vitamin-D receptors apparent- 
ly do not associate with Hsp90 [Dalman et al. 1990, Dalman et al. 1991, Whitfield et al. 1995].

Heat shock proteins are one of the most highly conserved group of proteins and are expressed in organisms ranging from bacteria to practically all eukaryote cell types [Bardwell and Craig 1984, Hunt and Morimoto 1985]. Although termed heat shock proteins, most of them are constitutively expressed at significant levels at all physiological temperatures [Kelley and Schlesinger 1982] [Welch and Feramisco 1982]. Their expression is enhanced in consequence of a wide variety of environmental assaults such as increased temperature, metabolic poisons, alcohol and toxins [Burdon 1986]. The response to such noxious conditions is now more often referred to as a stress response and the proteins in question as stress proteins. Intracellular accumulation of abnormally folded polypeptides constitutes a trigger for the initiation of the stress response [Welch 1992]. Stress proteins belong to a large family of unrelated protein classes called chaperones [Hemmingsen et al. 1988]. These molecular chaperones promote correct folding of a newly synthetized polypeptide into a functional protein by recognizing and binding non-native proteins, thus preventing aggregation and retaining the proteins in the productive folding pathway. The folding takes place sequentially through several intermediates. Chaperones are involved in all stages of protein metabolism: protein folding, oligomeric assembly, transport to a particular subcellular compartment and targeting proteins for degradation [Ellis and van der Vies 1991].

There is evidence that Hsp90 is a cytoplasmic protein and that there is not a sufficient amount of Hsp90 molecules in the nucleus to form complexes with nuclear steroid receptors [Tuohimaa et al. 1993]. There is, however, evidence that the glucocorticoid receptor (GR), which is predominantly cytoplasmic in its unoccupied form, can be crosslinked in vivo with Hsp90, which would imply that steroid receptors may be associated with Hsp90 in the cytoplasmic compartment. [Rexin et al. 1991]. At elevated temperature, the interaction of the receptorassociated proteins and steroid receptors is a dynamic process; the complex is dissociated with a half-life of 5 minutes and the assembly is reinitiated. [Smith 1993]. At low temperatures, the energydependent nuclear import is prevented, whereas the nuclear export is still functional [Guiochon-Mantel et al. 1991]. Cold treatment also stabilizes the oligomeric complex [Grody et al. 1982]. It is difficult to study the association in vivo in living cells. We have raised an antibody, termed $\alpha \mathrm{D}$, against the hinge domain (domain D) of the chicken PR. This antibody recognizes only the dissociated form and not the oligomeric complex of the PR in tissue homogenates [Pekki et al. 1995]. In order to study the oligomeric complex in intact cells in vivo, we used this antibody and showed that the epitope is fully detectable by immunohistochemistry, even though all the receptors extracted from these tissues are in oligomeric form and are thus not recognized by the antibody. However, inability to detect the complex could be attributable to the fore-mentioned dynamic interaction. In the present work we focused on the oligomeric complex in cells in which the dynamic interaction was stabilized by either molybdate or cold treatment, both of which have been shown to stabilize the complex. The results suggest that most receptors are in dissociated form in the nucleus.

\section{Materials and Methods}

\section{Cell culture, transfection and expression vectors}

Cos-7 cells were grown on glass coverslips and maintained in DMEM (Life Technologies, Gaitersburg) supplemented with 5\% charcoal-stripped fetal bovine serum. The cells were transfected by lipofection using Lipofectamine reagent (Life Technologies) according to manufacturer's instructions. They were incubated with serum-free Optimem (Life Technologies) containing the DNA-liposome-complexes for $24 \mathrm{~h}$ at $37^{\circ} \mathrm{C}$ and thereafter in medium with $10 \%$ charcoal-stripped fetal bovine serum for $2 \mathrm{~h}$; the medium was changed and the cells further incubated for $24 \mathrm{~h}$. Wild-type chicken progesterone receptor (cPR21) and wild-type chicken Hsp90 expression vectors were used and have been described elsewhere [Tuohimaa et al. 1993, Turcotte et al. 1990].

\section{Cold treatment}

Immediately after $24 \mathrm{~h}$ incubation following transfection, the cells were rinsed with DMEM supplemented with $5 \%$ charcoal-stripped FBS at $4{ }^{\circ} \mathrm{C}$ and thereafter incubated on ice for $4 \mathrm{~h}$. Following cold treatment, they were rinsed three times with PBS and fixed in $4 \%$ paraformaldehyde. 


\section{Molybdate treatment}

After $24 \mathrm{~h}$ incubation, the transfected cells were washed three times with PBS, then switched to phenol red-free DMEM plus 10\% charcoal-stripped FBS and incubated for 8-10h. Immediately preceding molybdate addition, cells were rinsed with PBS. Molybdate was added to attain a final concentration of $40 \mathrm{mM}$ and lipofectamine reagent (2 $\mathrm{mg} / \mathrm{mL}$; Life Technologies) was diluted 1:333 in phenol red-free and serum-free DMEM and the mixture incubated at room temperature for $40 \mathrm{~min}$. The lipofectamine/molybdate solution was then applied to the cells and they were incubated overnight at $37 \mathrm{C}$. Thereafter, the cells were rinsed with PBS three times and fixed in $4 \%$ paraformaldehyde.

\section{Antibodies}

We used two monoclonal antibodies, PR22 and $7 D \alpha$, and polyclonal antibody $\alpha \mathrm{D}$. PR22 is a mouse monoclonal antibody which recognizes the chicken PR [Sullivan et al. 1986]. We raised polyclonal antibody $(\alpha D)$, which can distinguish between the oligomeric and dissociated form of the chicken PR [Pekki et al. 1995]. Monoclonal antibody 7D $\alpha$ is chicken Hsp90-specific, recognizing both free Hsp90 and the Hsp90 in the oligomeric PR complex [Schuh et al. 1985]. The mouse monoclonal antibody $P R 6$ raised against $P R$ recognizes only the B component of PR [Sullivan et al. 1986].

\section{Histochemical techniques}

In order to compare the immunostaining of the two antibodies in the same cells, we used a double immunofluorescence labelling technique. The polyclonal antibody $\alpha D$ was combined with one of the monoclonal antibodies ( $\alpha$ D/PR22, $\alpha$ D/PR6 or $\alpha D / 7 D \alpha)$. After fixation, the cells were washed in PBS for $10 \mathrm{~min}$, incubated in $0.5 \%$ Triton-x-100 in PBS for $40 \mathrm{~min}$ at room temperature and washed in PBS for $10 \mathrm{~min}$. They were then incubated in $10 \%$ normal rabbit and horse serum in PBS for 30 min. PR 22 and $\alpha D, P R 6$ and $\alpha D$ antibodies as well as $\alpha D$ and 7D $\alpha$ were mixed and applied to sections and incubated $0 / \mathrm{N}$. The monoclonal antibodies PR22 and 7D $\alpha$ were used at a final concentration of $1 \mu \mathrm{g} / \mathrm{mL}$, PR6 at a final concentration of 1:500 and the polyclonal antibody $\alpha \mathrm{D}$ in a dilution of $1: 200$. The next day, cells were washed in PBS for 10 min, incubated with secondary antibodies, namely a biotinylated anti-mouse antibody (from goat, Amersham) dilution of $1: 400$ and an antirabbit-antibody Fluorescein dilution of $1: 200$ in PBS for $40 \mathrm{~min}$. The secondary antibodies were added to the sections simultaneously. The cells were then washed in PBS for 10 min and incubated with rhodamin-labeled avidin D 1:100-150 in PBS for 30 min followed by washing in PBS for 10 min and mounting in phenylenediamine-glycerine $(50 \mathrm{mg}$ phenylenediamine was diluted in $5 \mathrm{~mL}$ PBS, filtrated and added to $45 \mathrm{~mL}$ glycerine. $\mathrm{pH}$ was adjusted to 9.0 with $0.5 \mathrm{M}$ carbonate buffer). The results were analyzed by confocal microscopy.

\section{Confocal microscopy}

A confocal microscope, Bio-Rad MRC1024 (BioRad, Cambridge, Mass) connected to a Zeiss Axiovert 135M (Carl Zeiss Jena GMbH, Göttingen, Germany) inverted microscope was used. The laser was argon/krypton (American Laser Corporation, Salt Lake City, Utah). FITC-stained samples were imaged by excitation at $488 \mathrm{~nm}$ with a 506-541 nm band pass emission filter. TRITC-stained exitation at $568 \mathrm{~nm}$ long pass emission filter. The different fluorophores were imaged separately to ensure pictures with no excitation/emission wavelength overlap; the separate images were merged into a single image later.

\section{Results}

\section{Molybdate stabilization}

The hetero-oligomeric complex of the PR was studied in Cos-7 cells which were transfected with the whole length B-form of the chicken PR CDNA. The receptor was detected using double immunohistochemistry with two antibodies. These antibodies have different epitopes: PR22 and PR6 recognize an epitope in the aminoterminal region of the $\mathrm{PR}$ and can detect both oligomeric and dissociated forms of the PR, whereas $\alpha D$ recognizes an epitope (D-domain) which is masked in the heterooligomeric complex and which thus recognizes only the dissociated form. For cell fixation, we used a crosslinking fixative, paraformaldehyde, and immunostaining was studied by confocal microscopy. When transiently expressed, PR was studied with PR22 (Figure 1D) and PR6 (Figure 1C) (in cells not treated with molybdate); in most of the cells only nuclear staining was detected. As also previously observed, about 15\% of cells showed faint 

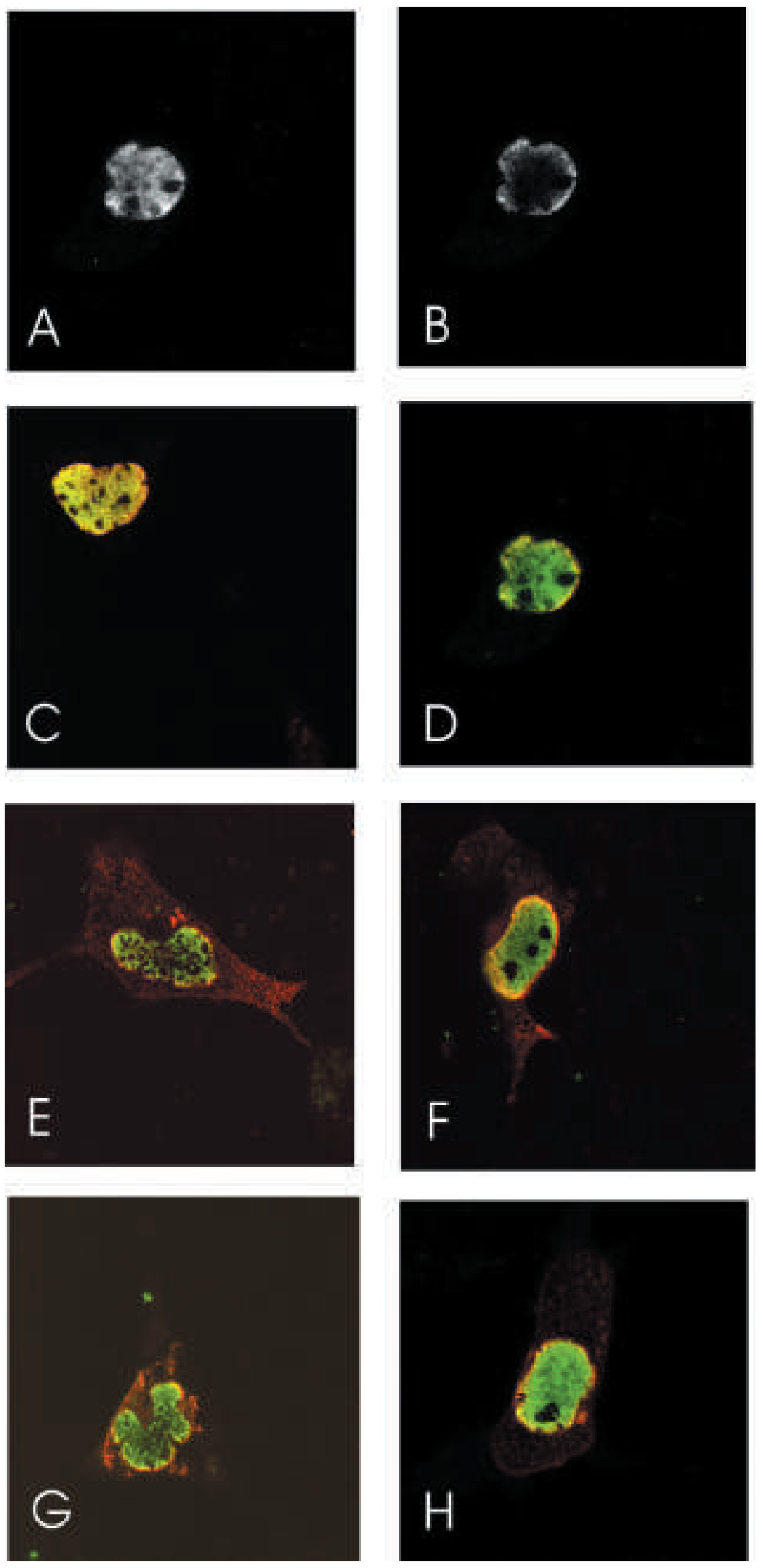

Figure 1. The detection of progesterone receptor with antibodies PR22, PR6 and $\alpha D$. The whole length B-form of the chicken PR cDNA was transfected into Cos Cos-7 cells. Double immunofluorescence staining of PR were performed with antibodies PR22 (rhodamin) and $\alpha \mathrm{D}$ (fluorescein) shown as single stains in a) $\alpha D$ and b) PR22 or in d) as double staining. c) Double immunostaining with antibody pair PR6 (rhodamin)/ $\alpha D$ (fluorescein). We used molybdate e) PR6 (rhodamin) $/ \alpha D$ (fluorescein), f) PR22 (rhodamin) $/ \alpha D$ (fluorescein) and cold treatment $g$ ) PR6 $/ \alpha D$ h) PR22 $/ \alpha D$ to stabilize the oligomeric complex. The stainings were carried out by double immunofluorescence technique and the results analyzed by confocal microscopy. 
cytoplasmic staining when stained with the PR22. When the same cells were stained with the $\alpha \mathrm{D}$ antibody, only nuclear staining was detected. Interestingly, PR22 stained predominantly the nuclear periphery whereas $\alpha D$ stained both the nuclear periphery, and the center (Figure $1 A, B$ ). Since the nuclear envelope cannot be visualized, it cannot be excluded that part of the staining was perinuclear (cytoplasmic).

Molybdate is known to stabilize oligomeric steroid receptor complexes in vitro in cell lysates [Raaka et al. 1985]. The relative impermeability of the plasma membrane to molybdate has hampered its use for stabilizing receptor oligomers in vivo. However, Yand and DeFranco have successfully used liposomes to deliver divalent molybdate anion to living cells for stabilization of oligomeric receptor complexes [Yang and DeFranco 1996]. When PR-transfected Cos-7 cells were grown in the presence of molybdate and stained with PR22 or PR6, PR was seen to accumulate in the cytoplasm (Figures $1 \mathrm{E}, \mathrm{F}$ ). The nuclear periphery was also stained as in the nontreated cells. When the same cells were stained with $\alpha D$, staining was seen predominantly in the nucleus, with faint cytoplasmic staining (Figures $1 \mathrm{E}, \mathrm{F}$ ). Co-transfection of Hsp90 into the cells together with the PR did not change the staining pattern (data not shown). The transiently transfected Hsp90 was seen to be located exclusively in the cytoplasm.

\section{Cold treatment}

When PR-transfected Cos-7 cells were incubated at $4^{\circ} \mathrm{C}$ for 4 hours in the absence of the ligand and the PR visualized with PR22 and PR6, intensive cytoplasmic staining was seen (Figures $1 G, H$ ). As in the molybdate-treated cells, the nuclear periphery was also stained. When the same cells were stained with $\alpha \mathrm{D}$, intense nuclear staining was detected, with faint cytoplasmic staining (Figures $1 G, H)$. Co-transfection of the Hsp90 with the wild type PR did not alter the staining pattern.

\section{Discussion}

In the present work we used an antibody, $\alpha \mathrm{D}$, raised against a region of $P R$ which is required for the stability of the oligomeric form. The antibody does not recognize the native oligomeric form in the cytosol. The major components of the oligomeric complex in the cytosol include the receptor, Hsp90, p23 and one of the immunophilins [Johnson and Toft 1994]. Since p23 and the immunphilins are though to be associated with the complex through the Hsp90, it is most probably the latter which is responsible for masking the $\alpha \mathrm{D}$ epitope. In a previous immunohistochemical study, we showed that $\alpha D$ can recognize endogenous $P R$ in the nucleus of chicken oviduct cells, indicating that the epitope is readily accessible, and furthermore, that most of the PR molecules in the cell nucleus are in dissociated form [Tuohimaa et al. 1993]. In addition, we have previously shown that fixation does not cause artificial exposure of the epitope [Pekki and Tuohimaa 1989]. When PR-transfected Cos-7 cells were treated with molybdate or incubated in cold to stabilize the oligomeric complex, a portion of the nuclear receptor was seen to be translocated into the cytoplasm. The cytoplasmic receptor was detected with PR22 or PR6, whereas $\alpha$ D showed nuclear staining. In the nucleus, the PR22 stained preferentially the nuclear periphery, and to a lesser extent, the central parts of the nucleus. The reason for this weak staining in the nuclear center is not clear but the same phenomenon has been reported by Chandran and DeFranco [Chandran and DeFranco 1992]. The $\alpha D$ antibody, in contrast, shows marked staining throughout the nucleus except for the nucleoli. The strong staining of the nuclear PR with $\alpha D$ indicates that the epitope is readily exposed in the nuclear PR. Taken together, these results suggest that only a fraction of receptors can form complexes with Hsp90 in the cytoplasm, whereas most, if not all of the nuclear receptors are Hsp90-free. Coexpression of Hsp90 did not alter the staining pattern, indicating that the results were not due to an insufficient amount of endogenous Hsp90. The transiently expressed chicken Hsp90 was located in the cytoplasm, which is consistent with the location of the endogenous $\mathrm{Hsp} 90$ in the chicken oviduct.

There are four lines of evidence suggesting an association of $\mathrm{Hsp90}$ with steroid receptors in vivo in living cells: overexpression of unliganded LBD of $P R$ and $G R$, but not liganded LBD, activates endogenous heat shock factor, proposing that the nonliganded LBD of steroid receptors can interact with heat-shock proteins in vivo [Xiao and DeFranco 1997], in vivo crosslinking studies and cotranslocation studies with mutated receptors and experiments performed with NLS-tagged Hsp90 [Alexis et al. 1992, Kang et al. 1994, Rexin et al. 1992]. In crosslinking studies, where living cells were treated 
with a bifunctional crosslinker agent, Hsp90 and p53 could be identified as GR binding partners [Alexis et al. 1992, Rexin et al. 1992]. Conflicting results have been reported for the crosslinking of ER in intact MCF-7 cells. Rossini and Camellini (1994) reported that an unidentified $50 \mathrm{kD}$ protein but not Hsp90 was associated with the ER, whereas Segnitz and Gehring (1995), showed that both Hsp90 and p59 can be crosslinked to ER in intact cells. The reason for this discrepancy remains unclear, but it should be noted that in the experiment by Segnitz and Gehring, the cells were incubated for 2 hours at $0^{\circ} \mathrm{C}$ prior to crosslinking. Such treatment is known to inhibit nuclear translocation and result in cytoplasmic accumulation of steroid receptors [Guiochon-Mantel et al. 1991]. The possibility cannot thus be entirely excluded that the crosslinked species does not represent a cytoplasmic complex. In cotranslocation studies, a recombinant $\mathrm{Hsp90}$, carrying a heterologous nuclear localization signal, cotransported a fraction of cytoplasmic steroid receptor mutant into the nucleus when coexpressed in the same cells [Kang et al. 1994, Passinen et al. 1999]. These authors reasoned that if NLS-Hsp90 could transport the cytoplasmic receptor into the nucleus, intact steroid receptors should reciprocally co-transport cytoplasmic Hsp90 into the nucleus. However, it has since been demonstrated that this is not the case, since overexpressed wild-type PR was incapable of significantly altering the cytoplasmic location of wild-type Hsp90. These results, together with those of the in vivo crosslinking studies and data presented in the present work, indicate a cytoplasmic association in vivo between steroid receptors and $\mathrm{Hsp90}$, but do not demonstrate receptorHsp90 interaction in the cell nucleus.

In crosslinking studies, non-liganded ER has been detected as a complex with chromatin proteins [Rossini and Camellini 1994]. In living cells in vivo, apo-receptors are probably associated with chromatin constituents [Wrenn and Katzenellenbogen 1990] and do not require Hsp90 for their stability. Interestingly, high-mobility group chromatin proteins 1 and 2 can interact with steroid receptors, but not with retinoic acid receptors or vitamin D receptors, and enhance DNA binding [Boonyaratanakornkit et al. 1998]. Analogously, purified Hsp90, but not Hsp70, can stimulate DNA binding of partially denatured ER [Sabbah et al. 1996]. The interaction with these chromatin proteins might serve as a support for the receptor to keep the hormone-binding domain as a functionally active conformation and thus complement the requirement of the Hsp90 interaction in vivo in the nucleus. Upon homogenization, the steroid receptors are released and their hydrophobic surfaces become exposed to an aqueous milieu. This induces $\mathrm{Hsp} 90$ binding, prevents receptor aggregation, and generates $8 \mathrm{~S}$ heterooligomers. Holoforms of steroid receptors, retinoic acid receptors and thyroid receptors, whose LBDs are more hydrophilic, are less amenable targets for Hsp interaction and thus cannot be seen as oligomeric complexes in tissue extracts [Hansen and Gorski 1985, Wurtz et al. 1996]. It may thus be concluded that the majority of progesterone receptors are in the nucleus associated with chromatin proteins. Upon homogenization, these highly hydrophobic molecules are released into an aqueous milieu which triggers the formation of the stable oligomeric complex, which in vivo in intact cells, can be seen as a transient complex after receptor synthesis and possibly also in the cytoplasm during receptor shuttling.

\section{Acknowledgments}

The authors are grateful to Ms Helena Vihinen for excellent help in using confocal microscopy, Hinrich Gronemeyer for cPR cDNA and David Toft for providing antibodies PR22 and PR6.

\section{References}

Alexis MN, Mavridou I, Mitsiou DJ. Subunit composition of the untransformed glucocorticoid receptor in the cytosol and in the cell. Eur J Biochem 1992;204:75-84.

Bardwell JG, CraigEA. Major heat shock gene of Drosophila and the Escherichia coli heat-inducible dnaK gene are homologous. Proc Natl Acad Sci USA 1984;81:848-52

Baulieu EE. Antihormone-steroid hormonal activity, heat-shock protein hsp 90 and receptors. Horm Res 1987;28:181-95.

Bohen SP, Kralli A, Yamamoto KR. Hold 'em and fold 'em: chaperones and signal transduction. Science 1995;268:1303-4.

Boonyaratanakornkit $\mathrm{V}$, Melvin $\mathrm{V}$, Prendergast $\mathrm{P}$, Altmann $\mathrm{M}$, Ronfani $L$, Bianchi, Taraseviciene $L$, et al. High-mobility group chromatin proteins 1 and 2 functionally interact with steroid hormone receptors to enhance their DNA binding in vitro and transcriptional activity in mammalian cells. Mol Cell Biol 1998;18:4471-87.

Bresnick EH, Dalman FC, Sanchez ER, Pratt WB. Evidence that the $90-\mathrm{kDa}$ heat shock protein is necessary for the steroid binding conformation of the $L$ cell glucocorticoid receptor. J Biol Chem 1989; 264:4992-7.

Burdon $\mathrm{RH}$. Heat shock and the heat shock proteins. Biochem J 1986;240:313-24.

Chandran UR, DeFranco DB. Internuclear migration of chicken progesterone receptor, but not simian virus-40 large tumor antigen, in transient heterokaryons. Mol Endocrinol 1992; 837-44.

Dalman FC, Koenig RJ, Perdew GH, Massa E, Pratt WB. In contrast to the glucocorticoid receptor, the thyroid hormone receptor is translated in the DNA binding state and is not associated with hsp90. J Biol Chem 1990;265:3615-8

Dalman, F.C, Sturzenbecker, L.J, Levin, A.A, Lucas, D.A, Perdew, G.H, Petkovitch, M, Chambon, P, Grippo, J.F, and Pratt, W.B. Retinoic 
acid receptor belongs to a subclass of nuclear receptors that do not form "docking" complexes with hsp90. Biochemistry, 30, 5605$5608,1991$.

Dougherty, J.J, Puri, R.K, and Toft, D.O. Polypeptide components of two $8 \mathrm{~S}$ forms of chicken oviduct progesterone receptor. J Biol Chem, 259, 8004-8009, 1984.

Ellis, R.J, and van der Vies, S.M. Molecular chaperones. Annu Rev Biochem, 60, 321-347, 1991.

Grody, W.W, Schrader, W.T, and O'Malley, B.W. Activation, transformation, and subunit structure of steroid hormone receptors. Endocr Rev, 3, 141-163, 1982.

Guiochon-Mantel, A, Lescop, P, Christin-Maitre, S, Loosfelt, H, PerrotApplanat, M, and Milgrom, E. Nucleocytoplasmic shuttling of the progesterone receptor. Embo J, 10, 3851-3859, 1991.

Hansen, J.C, and Gorski, J. Conformational and electrostatic properties of unoccupied and liganded estrogen receptors determined by aqueous two-phase partitioning. Biochemistry, 24, 6078-6085, 1985.

Hemmingsen, S.M, Woolford, C, van der Vies, S.M, Tilly, K, Dennis, D.T Georgopoulos, C.P, Hendrix, R.W, and Ellis, R.J. Homologous plant and bacterial proteins chaperone oligomeric protein assembly. Nature, 333, 330-334, 1988.

Hunt, C, Morimoto, R.I. Conserved features of eukaryotic hsp70 genes revealed by comparison with the nucleotide sequence of human hsp70. Proc Natl Acad Sci USA, 82, 6455-6459, 1985.

Johnson, JL, Toft, D.0. A novel chaperone complex for steroid receptors involving heat shock proteins, immunophilins, and p23.J Biol Chem, 269, 24989-24993, 1994.

Kang, KI, Devin, J, Cadepond, F, Jibard, N, Guiochon-Mantel, A, Baulieu, EE, Catelli, MG. In vivo functional protein-protein interaction: nuclear targeted hsp90 shifts cytoplasmic steroid receptor mutants into the nucleus. Proc Natl Acad Sci U S A, 91, 340-344, 1994.

Kelley PM, Schlesinger MJ. Antibodies to two major chicken heat shock proteins cross-react with similar proteins in widely divergent species. Mol Cell Biol 1982; 2:267-74.

Moras D, Gronemeyer $\mathrm{H}$. The nuclear receptor ligand-binding domain: structure and function. Curr Opin Cell Biol 1998; 10:384-91.

Passinen S, Haverinen M, Pekki A, Rauta J, Paranko J, Syvala H, Tuohimaa P, Ylikomi T. Only a small portion of the cytoplasmic progesterone receptor is associated with $\mathrm{Hsp} 90$ in vivo. J Cell Biochem 1999; 74:458-67.

Pekki A, Tuohimaa P. New freeze-dry and vapor fixation method for immunohistochemistry of soluble proteins: subcellular location of the progesterone receptor. J Histochem Cytochem 1989; 37: 120713.

Pekki A, Ylikomi T, Syvala H, Tuohimaa P. Progesterone receptor does not form oligomeric ( $8 \mathrm{~S})$, non-DNA-binding complex in intact cell nuclei. J Cell Biochem 1995; 58:95-104.

Picard D, Salser SJ, Yamamoto KR. A movable and regulable inactivation function within the steroid binding domain of the glucocorticoid receptor. Cell 1988; 54:1073-80.

Raaka BM, Finnerty M, Sun E, Samuels HH. Effects of molybdate on steroid receptors in intact $\mathrm{GHI}$ cells. Evidence for dissociation of an intracellular $10 \mathrm{~S}$ receptor oligomer prior to nuclear accumulation. J Biol Chem 1985; 260:14009-15.

Renaud, J.P, Rochel, N, Ruff, M, Vivat, V, Chambon, P, Gronemeyer, H, and Moras, D. Crystal structure of the RAR-gamma ligand-binding domain bound to all-trans retinoic acid. Nature 1995; 378:681-9.

Rexin M, Busch W, Gehring U. Protein components of the nonactivated glucocorticoid receptor. J Biol Chem 1991; 266:24601-5.
Rexin M, Busch W, Segnitz B, Gehring U. Structure of the glucocorticoid receptor in intact cells in the absence of hormone. J Biol Chem 1992; 267:9619-21.

Rossini GP, Camellini L. Oligomeric structures of cytosoluble estrogenreceptor complexes as studied by anti-estrogen receptor antibodies and chemical crosslinking of intact cells. J Steroid Biochem Mol Biol 1994; 50:241-52.

Sabbah M, Radanyi C, Redeuilh G, Baulieu EE. The 90 kDa heat-shock protein (hsp90) modulates the binding of the oestrogen receptor to its cognate DNA. Biochem J 1996; 314:205-13.

Scherrer LC, Picard D, Massa E, Harmon JM, Simons SS, Jr, Yamamoto KR, Pratt WB. Evidence that the hormone binding domain of steroid receptors confers hormonal control on chimeric proteins by determining their hormone- regulated binding to heatshock protein 90. Biochemistry 1993; 32:5381-6.

Schuh S, Yonemoto W, Brugge J, Bauer VJ, Riehl RM, Sullivan WP, Toft DO. A 90,000-dalton binding protein common to both steroid receptors and the Rous sarcoma virus transforming protein, pp60vsrc. J Biol Chem 1985; 260:14292-6.

Segnitz, B, and Gehring, U. Subunit structure of the nonactivated human estrogen receptor. Proc Natl Acad Sci USA 1995; 92:217983.

Smith, D.F. Dynamics of heat shock protein 90-progesterone receptor binding and the disactivation loop model for steroid receptor complexes. Mol Endocrinol 1993; 7:1418-29.

Sullivan WP, Beito TG, Proper J, Krco CJ, Toft DO. Preparation of monoclonal antibodies to the avian progesterone receptor. Endocrinology 1986; 119:1549-57.

Tuohimaa P, Pekki A, Blauer M, Joensuu T, Vilja P, Ylikomi, T. Nuclear progesterone receptor is mainly heat shock protein 90-free in vivo. Proc Natl Acad Sci USA 1993; 90:5848-52.

Turcotte, B, Meyer, M.E, Bocquel, M.T, Belanger, L, and Chambon, P. Repression of the alpha-fetoprotein gene promoter by progesterone and chimeric receptors in the presence of hormones and antihormones. Mol Cell Biol 1990; 10:5002-6.

Welch WJ. Mammalian stress response: cell physiology, structure/function of stress proteins, and implications for medicine and disease. Physiol Rev 1992; 72:1063-81.

Welch WJ, Feramisco JR. Purification of the major mammalian heat shock proteins. J Biol Chem 1982; 257:14949-59.

Whitfield GK, Hsieh JC, Nakajima, S, MacDonald PN, Thompson PD, Jurutka PW, Haussler CA, Haussler MR. A highly conserved region in the hormone-binding domain of the human vitamin $D$ receptor contains residues vital for heterodimerization with retinoid $X$ receptor and for transcriptional activation [published erratum appears in Mol Endocrinol 1995 Nov;9(11):1509]. Mol Endocrinol 1995; 9:1166-79.

Wrenn CK, Katzenellenbogen BS. Cross-linking of estrogen receptor to chromatin in intact MCF-7 human breast cancer cells: optimization and effect of ligand. Mol Endocrinol 1990; 4:1647-54.

Wurtz JM, Bourguet W, Renaud JP, Vivat V, Chambon P, Moras D, Gronemeyer $\mathrm{H}$. A canonical structure for the ligand-binding domain of nuclear receptors. Nat Struct Biol1996; 3:206.

Xiao N, DeFranco D.B. Overexpression of unliganded steroid receptors activates endogenous heat shock factor. Mol Endocrinol, 11, 13651374, 1997.

Yang J, DeFranco DB. Assessment of glucocorticoid receptor-heat shock protein 90 interactions in vivo during nucleocytoplasmic trafficking. Mol Endocrinol, 10, 3-13, 1996. 